\title{
Erratum to: Age-Related Changes in the Human Voice
}

\author{
Hideki Kasuya and Hajime Yoshida
}

\section{Erratum to:}

Chapter 3 in: Kiyoshi Makiyama / Shigeru Hirano (eds), Aging Voice, DOI 10.1007/978-981-10-3698-9_3

The labels in the figure 3.4 (a), (b) were incorrectly published. The same have been changed in the respective chapter as follows:

\section{ONNEb}

\section{$\triangle \mathrm{NNEa}$}

Fig. 3.4 (a) Longitudinal plots of NNEa and NNEb for a male. (b) Longitudinal plots of $\mathrm{NNEa}$ and $\mathrm{NNEb}$ for a female

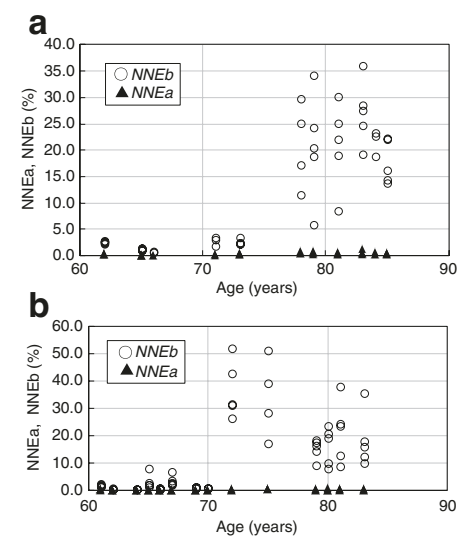
\footnotetext{
DOI 10.1007/978-981-10-3698-9_3

H. Kasuya $(\bowtie)$

Utsunomiya University, Utsunomiya, Japan

e-mail: kasuyah@snow.ucatv.ne.jp

H. Yoshida

Yoshida Hospital, Nayoro, Japan

e-mail: info_yoshida@rinseikai.jp

The updated original online version of this chapter can be found at 